\title{
Coupling of on-Line Pre-Column Oxidative Cleavage and Solid-Phase Enrichment with Liquid Chromatography Using an Eco-Friendly Analytical Procedure to Determine Low Levels of Methotrexate
}

\author{
Samy Emara ${ }^{1}$, Walaa Zarad ${ }^{1}$, Maha Kamal ${ }^{2}$, Ramzia EL-Bagary ${ }^{3}$ \\ ${ }^{1}$ Pharmaceutical Chemistry Department, Faculty of Pharmacy, Misr International University, Cairo, Egypt; ${ }^{2}$ Pharmaceutical Analyti- \\ cal Chemistry Department, Faculty of Pharmacy, Modern Sciences and Arts University, 6th of October City Egypt; ${ }^{3}$ Pharmaceutical \\ Chemistry Department, Faculty of Pharmacy, Cairo University, Giza, Egypt. \\ Email: *emara_miu@yahoo.com
}

Received September $28^{\text {th }}, 2012$; revised November $9^{\text {th }}, 2012$; accepted November $18^{\text {th }}, 2012$

\begin{abstract}
A simple, sensitive and precise green high-performance liquid chromatographic method including on-line pre-column oxidation combined by column switching with a short Hypersil ODS analytical column $(100 \mathrm{~mm} \times 4.0 \mathrm{~mm}$ i.d.) for enrichment and separation was developed and validated to determine low levels of methotrexate (MTX). The method was based on oxidative cleavage of MTX into highly fluorescence products, 2,4-diaminopteridine-6-carboxaldehyde and the corresponding 2,4-diaminopteridine-6-carboxylic acid, during the flow of phosphate buffer $(0.04 \mathrm{M}, \mathrm{pH} 3.4)$ containing the analyte through the packed reactor of cerium (IV) trihydroxyhydroperoxide (CTH) at a flow-rate of 0.2 $\mathrm{mL} / \mathrm{min}$ and $40^{\circ} \mathrm{C}$. The fluorescent products were enriched on the head of ODS analytical column for the final separation. The separation was performed at room temperature using an environmentally friendly mobile phase consisting of ethanol and phosphate buffer $(0.04 \mathrm{M}, \mathrm{pH} 3.4)$ in the ratio of 10:90 (v/v). The eluent was monitored at emission and excitation wavelengths of 463 and $367 \mathrm{~nm}$, respectively. The method was successfully applied, without any interference from the excipients, for the determination of drug in tablets and vials with a detection limit of $0.06 \mathrm{ng} / \mathrm{mL}$ from $500 \mu \mathrm{L}$ of sample MTX.
\end{abstract}

Keywords: Cerium (IV) Trihydroxyhydroperoxide; HPLC; Methotrexate; ODS Analytical Column; On-Line Pre-Column Oxidative Cleavage

\section{Introduction}

Methotrexate (MTX, 2,4-diamino-4-deoxy- $\mathrm{N}^{10}$-methylpteroglutamic acid) is one of the most widely used anticancer drugs and acts as an antimetabolite of folic acid. In high doses it is used in treatment of some solid tumors and leukemia. It is also used in a number of autoimmune diseases [1].

Many methods have been developed for the determination of MTX, including spectrofluorimetry [2-4], immunoassay [5], capillary electrophoresis [6,7] and highperformance liquid chromatography (HPLC) with UV detection [8-13]. Due to its higher sensitivity and selectivity, the measurement of low MTX level was more precise in the HPLC with fluorescence detection [14-25]. MTX does not show native fluorescence but it can be derivatized into strongly fluorescent product after variety

${ }^{*}$ Corresponding author. of successful analytical schemes. Several methodologies have been developed for the oxidation of MTX to a highly fluorescent product, 2,4-diaminopteridine-6-carboxaldehyde and the corresponding 2,4-diaminopteridine-6-carboxylic acid. These methods were based on photo-oxidative irradiation at $254 \mathrm{~nm}[14,19,20,23,24]$, electrochemical oxidation $[16,17]$, oxidation with permanganate [4,18,25] and hydrogen peroxide [22-24]. Also, flow injection analysis (FIA) of MTX in pharmaceutical formulations has been reported [26,27]. These methods are based on the oxidation of the MTX into highly fluorescent product 2,4-diaminopteridine-6-carboxylic acid by on-line electrochemical oxidation and acidic potassium permanganate; respectively. A sequential injection analysis has also been reported for the determination of MTX using amperometric biosensor detector [28]. Cerium (IV) trihydroxyhydroperoxide (CTH) has been introduced as a packed reactor in a flowing system for conversion of 
MTX into a highly fluorescent 2,4-diaminopteridine-6carboxaldehyde and the corresponding 2,4-diaminopteridine-6-carboxylic acid (Figure 1) [29]. The United State Pharmacopoeia for the determination of MTX is based on HPLC with UV detection at $302 \mathrm{~nm}$ [30].

In recent years, more strict regulation related to the quality control of pharmaceuticals led to increasing demands on automation of the analytical assays carried out in appropriate control laboratories. Also, greener analytical methods, which minimize the use of toxic chemicals and/or eliminate the generation of toxic wastes, are strongly demanded, in order to prevent the environmental pollution and human hazards. Therefore, our study was involved in a research effort aimed to expand the automation by incorporating oxidation and pre-concentration steps prior to HPLC separation of MTX in an automated green procedure using column switching technique. A packed reactor FIA method coupled with on-line solid phase enrichment (SPEn) on a head of ODS analytical column for the final separation was established for the determination of MTX. The on-line pre-column procedure includes injecting MTX into a flowing stream of $0.04 \mathrm{M}$ phosphate buffer ( $\mathrm{pH}$ 3.4) carried through the packed reactor of $\mathrm{CTH}$ for oxidation. In such a way, the sample zone meets the $\mathrm{CTH}$ packed reactor in a controlled manner while the rest of the system is filled with phosphate buffer. Accordingly, reagent consumption is greatly decreased and the system is simplified with fewer junctions for mixing of reagent, sample and carrier
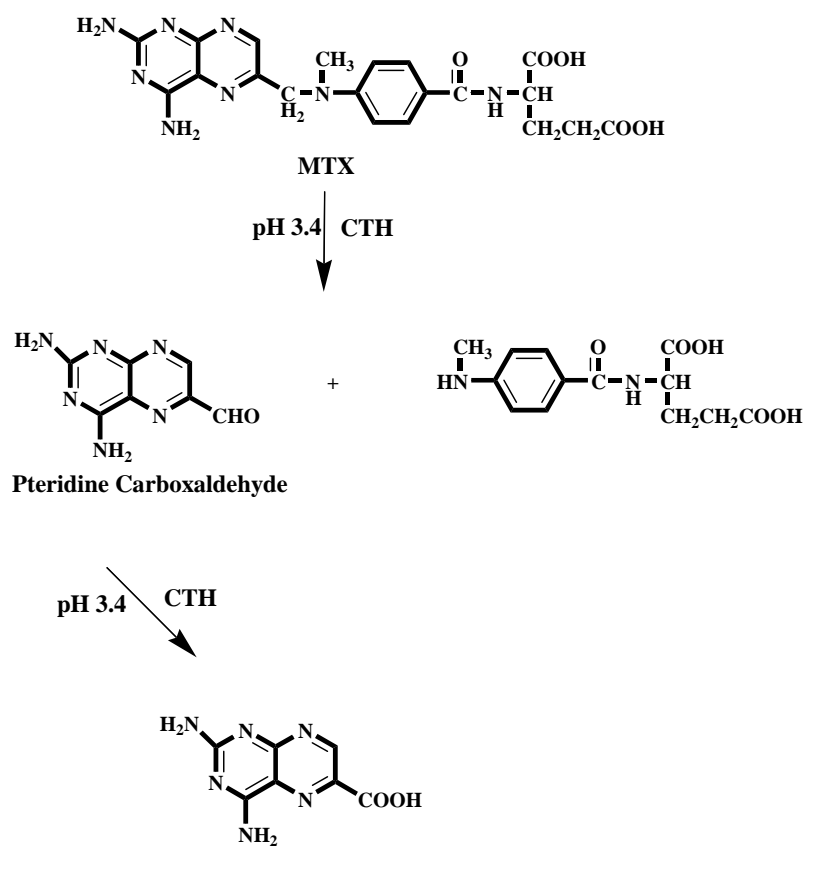

Pteridine Carboxylic acid

Figure 1. Structures of the investigated compounds. streams. The application of phosphate buffer as a flowing stream and CTH as a packed reactor are considered to be the main approaches complying with green analytical chemistry principles. Also, pre-concentration online before HPLC separation could enhance concentration detection limits of MTX. A particularly attractive feature of this method was that a simple green isocratic analytical mobile phase consisting of ethanol and $0.04 \mathrm{M}$ phosphate buffer ( $\mathrm{pH} 3.4)$ in the ratio of 10:90 (v/v) could be used for chromatographic separation of the fluorescent products on a short Hypersil ODS analytical column. The online oxidative cleavage-SPEn-HPLC separation strategy with fluorescence detection appeared to be a viable approach for the determination of MTX in pharmaceutical formulation down to a level of $0.20 \mathrm{ng} / \mathrm{mL}$. The results were evaluated by parallel experiments and analysis using the procedure recommended by the USP based on conventional HPLC method.

\section{Experimental}

\subsection{Reagents}

MTX (99.83\%) was obtained from Kyowa Hakki (Tokyo, Japan). The present method was applied to the determination of MTX in its pharmaceutical formulations: 1) Methotrexate tablets (Batch No. 1368454) $2.5 \mathrm{mg}$ of MTX; 2) Methotrexate vials (Batch No. 1236627) $50 \mathrm{mg}$ of MTX (Orion Corporation, Finland). Ethanol used was HPLC grade (BDH, Poole, UK). Distilled water was used for the preparation of all reagents and solutions. Potassium dihydrogen phosphate, ortho-phosphoric acid and isopropyl alcohol used were analytical grades.

\subsection{Instrumentation}

The HPLC (Agilent Technologies, CA, USA) apparatus, illustrated in Figure 2, consisted of two solvent delivery pumps (Agilent 1100 Series Iso pump G1310A). One used to deliver the carrier solution at a flow-rate of 0.2 $\mathrm{mL} / \mathrm{min}$ and the other to deliver isocratic mobile phase at a flow-rate of $1 \mathrm{~mL} / \mathrm{min}$. A model 7125 sample injection valve $(500 \mu \mathrm{L})$ and a model 7010 flow direction switching valve were applied to load the sample onto the CTH packed reactor and facilitate oxidative cleavage of MTX into highly fluorescence products and to control the flow direction switching and isocratic elution, respectively (Rheodyne, Berkeley, CA, USA). This system was equipped with two columns; one was a short $(50 \times 7.5 \mathrm{~mm}$ i.d. $) \mathrm{CTH}$ oxidant column for oxidative-cleavage of MTX into highly fluorescent products and the other was an analytical column of Thermo Scientific Hypersil ODS (100 $\times$ $4.0 \mathrm{~mm}$ i.d., $5 \mu \mathrm{m}$ particle size from Thermo Scientific, FL, USA). A fluorescence detector monitored the eluents, (Agilent 1200 series, G1321A) set at an excitation wave- 
length of $367 \mathrm{~nm}$ and an emission wavelength of 463 nm. Data acquisition was performed on Agilent LC ChemStation software. The analytical column temperature was ambient, while that of the $\mathrm{CTH}$ packed reactor was $40^{\circ} \mathrm{C}$.

\subsection{Standard Solution and Calibration}

Stock standard solution of MTX $(10 \mu \mathrm{g} / \mathrm{mL})$ was prepared by dissolving an accurately weighed amount of MTX in distilled water. A known volume of the stock standard solution was diluted with the same solvent to obtain a concentration of $1 \mu \mathrm{g} / \mathrm{mL}$ MTX (solution A). The standard solutions for calibration were prepared daily by serial dilutions of appropriate volumes of solution A to produce MTX in the final concentration range of $1-40 \mathrm{ng} / \mathrm{mL}$. An aliquot of $500 \mu \mathrm{L}$ was analyzed for MTX according to the proposed procedure. The stock standard solutions were stored frozen at $-20^{\circ} \mathrm{C}$ until used.

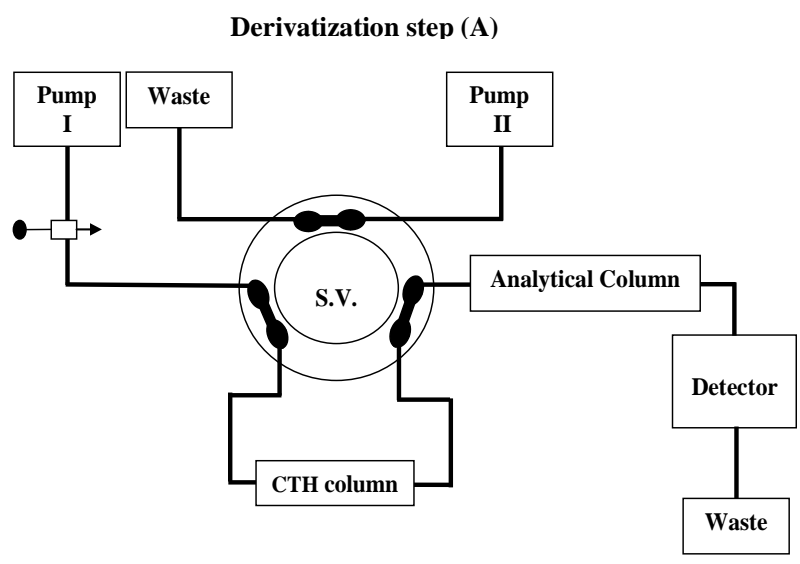

Separation step (B)

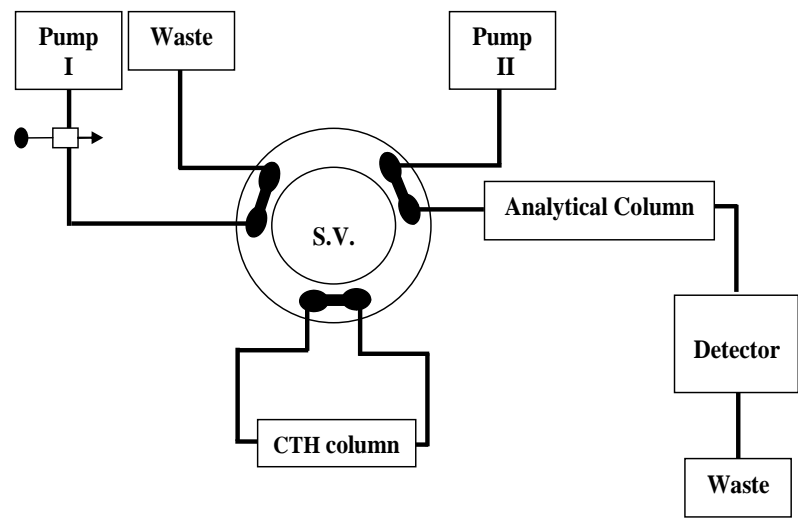

Figure 2. Schematic diagram of the online pre-column HPLC for the analysis of MTX in pharmaceutical formulation: the system in initial position, ready for sample injection, derivatization and enrichment steps (A); the separation step, in which the CTH column is isolated from HPLC circulation (B) (S.V.: six-port switching valve).

\subsection{Tablets}

A total of 20 tablets containing MTX as the active ingredient were weighed and finally powdered. A portion of the powder equivalent to $10 \mathrm{mg}$ of MTX was accurately weighed and transferred to a $100 \mathrm{~mL}$ calibrated flask and dissolved in about $90 \mathrm{~mL}$ of distilled water using an ultra sonic bath. The solution was diluted to the volume with the same solvent and then filtered. The first portion of the filtrate was discarded and the remainder was used as a stock sample solution (solution A, $100 \mu \mathrm{g} / \mathrm{mL}$ ). A known volume of solution A was diluted quantitatively with distilled water to obtain a concentration of $1 \mu \mathrm{g} / \mathrm{mL}$ MTX (solution B). A further dilution was carried out to obtain a final concentration of $20 \mathrm{ng} / \mathrm{mL}$ MTX. An aliquot of $500 \mu \mathrm{L}$ was analyzed for MTX according to the proposed procedure. The standard solutions for calibration were freshly prepared and stored in dark flask at $5^{\circ} \mathrm{C}$ during use.

\subsection{Vials}

An accurately volume equivalent to $10 \mathrm{mg}$ MTX was transferred to a $100 \mathrm{~mL}$ calibrated flask and completed to the mark with distilled water. Serial dilutions as described under tablets were made to obtain final concentration of $20 \mathrm{ng} / \mathrm{mL}$. An aliquot of $500 \mu \mathrm{L}$ was analyzed for MTX according to the proposed procedure.

\subsection{Preparation of CTH Column}

The CTH packing materials were suspended in isopropyl alcohol and degassed under vacuum with continuous stirring for $10 \mathrm{~min}$. A stainless-steel cylinder $(100 \mathrm{~mm} \times$ $7.5 \mathrm{~mm}$ i.d.) was used as a reservoir for the $\mathrm{CTH}$ packing materials. This reservoir was connected to short column (50 $\mathrm{mm} \times 7.5 \mathrm{~mm}$ i.d.) and the suspended CTH supplied from the reservoir was packed into the column with the aid of an HPLC pump at flow-rate of $5 \mathrm{~mL} / \mathrm{min}$ with ethanol as a purge solvent (10 min). Pumping must continue until a constant pressure is reached. The cylinder was then disconnected and a mixture of ethanol and distilled water $(1: 1)$ was passed through the column at a flow-rate of $1 \mathrm{~mL} / \mathrm{min}$ for further $10 \mathrm{~min}$. The column was then equilibrated with $0.04 \mathrm{M}$ phosphate buffer of $\mathrm{pH} 3.4$ at a flow-rate of $1 \mathrm{~mL} / \mathrm{min}$ for $30 \mathrm{~min}$.

\subsection{Mobile Phases}

Two different mobile phases were employed in the assay procedure; one was phosphate buffer $(0.04 \mathrm{M}, \mathrm{pH} 3.4)$, which was used as a carrier stream (MI) to deliver the sample to the CTH packed reactor in the oxidation step. The other was an isocratic solvent system (MII) consisting of ethanol and phosphate buffer $(0.04 \mathrm{M}, \mathrm{pH} 3.4)$ $(10: 90 \mathrm{v} / \mathrm{v})$ which was used to elute the enriched fluo- 
rescent products from the head of the Thermo Scientific Hypersil ODS analytical column to the fluorescence detector for further separation. All mobile phases were freshly prepared on the day of use, filtered through 0.45 $\mu \mathrm{m}$ filters (Millipore, Billerica, MA), and degassed ultrasonically under vacuum.

\subsection{General Procedure}

A $500 \mu \mathrm{L}$ aliquot of MTX sample was loaded into the injection valve and then injected into MI. The moving zone of MTX passed through the CTH column at a flowrate of $0.2 \mathrm{~mL} / \mathrm{min}$ (pump I). The oxidative cleavage of MTX occurs during the flow of MI containing the drug through the $\mathrm{CTH}$ column. Pre-concentration was performed by means of the flow of the fluorescent products from the oxidant column to the analytical column head. After 6 min the valve was switched into position B (Figure 2). At this position, the MII could pass directly through the analytical column, where the fluorescent 2,4-diaminopteridine-6-carboxaldehyde and the corresponding 2,4-diaminopteridine-6-carboxylic acid were then separated. The flow-rate was maintained at $1 \mathrm{~mL} /$ min and the fluorescence intensity of the eluting compounds was monitored at emission and excitation wavelengths of 463 and $367 \mathrm{~nm}$, respectively. At 9 min after injection, the valve was switched into position A (Figure 2).

\section{Result \& Discussion}

In order to apply $\mathrm{CTH}$ as a packed oxidant reactor, in the described manifold (Figure 2), the optimization of developed system was investigated considering particularly the effect of the $\mathrm{pH}$, concentration and flow rate of carrier stream (MI), sample volume and packed reactor temperature. During the phase of optimization of the chromatographic system, analytical mobile phase (MII) was investigated to evaluate the effect of the solvent composition and $\mathrm{pH}$ on the compounds separation. The detection wavelengths were chosen using the spectrum mode of the fluorescence detection with respect to the maximum sample signals. This mode enabled the determination of the optimum emission and excitation wavelengths in real conditions during measurement. The final measurement conditions were at emission and excitation wavelengths of 463 and $367 \mathrm{~nm}$, respectively.

\subsection{Effect of $\mathbf{p H}$ and Concentration of Carrier Stream}

Adjustment of the carrier stream $\mathrm{pH}$ was necessary to improve the reaction completeness between the analyte and CTH packed reactor. The effect of this parameter was studied in the $\mathrm{pH}$ range 2.8 - 5 using buffer solutions from phosphate and acetate. Phosphate buffer gave the best performance as a carrier stream and was selected in all further experiments. As shown in Figure 3, the pH of buffer solution affected the fluorescent derivatization of MTX severely. The highest intensity was observed in the narrow range of $\mathrm{pH} 3.2$ - 3.6 (Figure 3). At $\mathrm{pH}<3.0$, a low signal response was observed which might suggest the decomposition of the peroxy groups of the CTH materials, whereas at $\mathrm{pH}>3.8$, the detector signals was decreased abruptly probably due to the low CTH reactor efficiency which reduces drastically the oxidative cleavage of MTX into highly fluorescent derivative. Accordingly, phosphate buffer solution of $\mathrm{pH} 3.4$ was selected as the optimum carrier stream.

The variation in the fluorescent intensity of MTX with CTH packed oxidant was examined using phosphate buffer of concentrations varying from 0.02 to $0.1 \mathrm{M}$. Best analytical signals were verified within the concentration range $0.02-0.05 \mathrm{M}$ (Figure 4). With increasing the concentration of buffer, the detector response was drastically decreased, probably due to greater quenching effect on the fluorescence signal intensity. Although, $0.02 \mathrm{M}$ phosphate buffer showed slight improvement of signal intensity, $0.04 \mathrm{M}$ was chosen as a compromise between detector response and precision.

\subsection{Effect of Temperature}

The packed reactor temperature also has a critical effect on the reaction progress. The effect of this parameter on the derivatization of MTX with CTH packed oxidant into highly fluorescent derivatives was investigated in the range of $25^{\circ} \mathrm{C}-65^{\circ} \mathrm{C}$. Lower temperatures were inadequate whereas elevating the temperature within the range of $25^{\circ} \mathrm{C}-65^{\circ} \mathrm{C}$ resulted in an increase in the reaction rate and subsequently detector response (Figure 5). It was also observed that heating slightly above $45^{\circ} \mathrm{C}$ resulted in an increase of column pressure and showed a generally

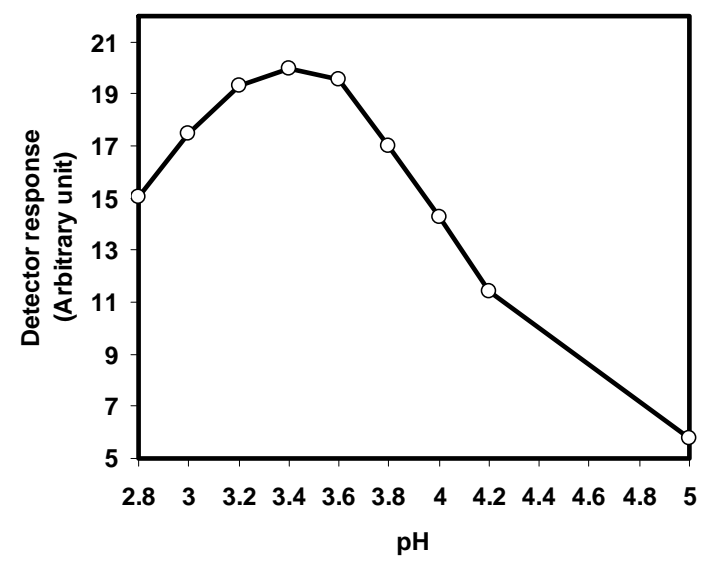

Figure 3. Effect of phosphate buffer $\mathrm{pH}$ on the reaction efficiency of CTH-packed reactor with MTX. 


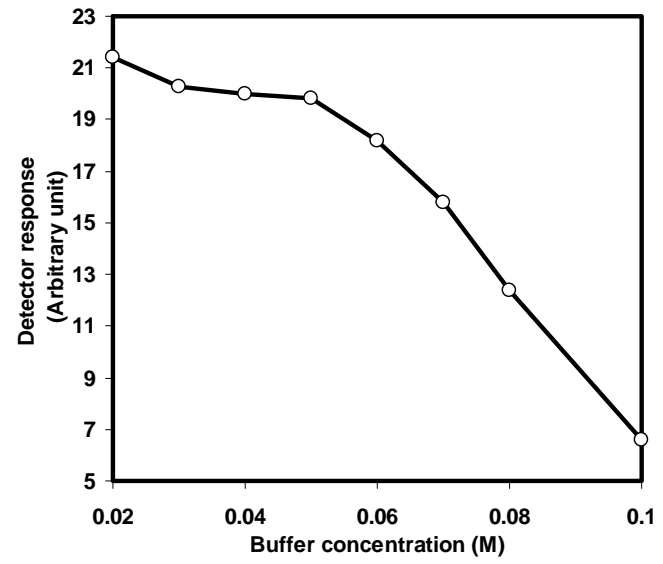

Figure 4. Effect of phosphate buffer concentration on the reaction efficiency of CTH-packed reactor with MTX.

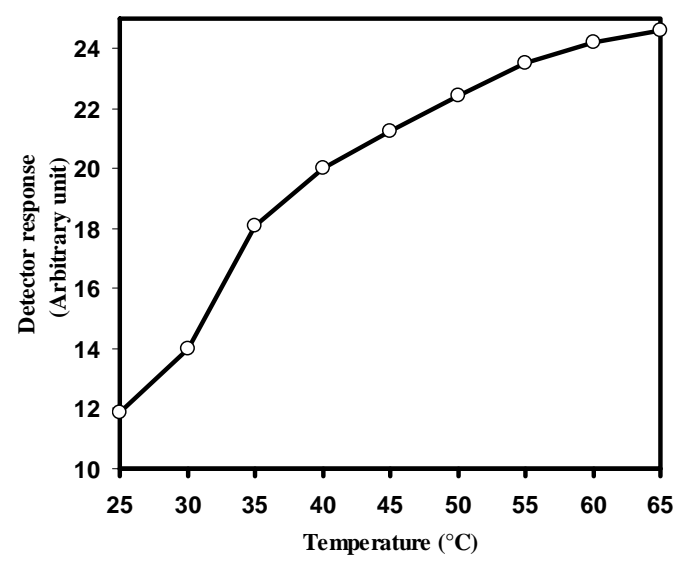

Figure 5. Effect of temperature on the reaction efficiency of CTH-packed reactor with MTX.

drastic effect on the CTH packed oxidant life span. Considering the effective reaction temperature and the packed oxidant limitations, $40^{\circ} \mathrm{C}$ was selected as the optimum value because under this condition good sensitiveity and reproducibility were achieved.

\subsection{Effect of the Flow Rate}

The reaction of CTH column with MTX was highly influenced by the flow-rate of the carrier stream. The use of rapid analyte transport into and out of the packed reactor would be advantageous for the fast analysis; however, it was also essential that the flow-rate of the carrier stream not to be so rapid as to compromise the extent of the analyte in the packed reactor. The effect of the flowrate was checked over the range of $0.2-0.8 \mathrm{~mL} / \mathrm{min}$. When the flow-rate was reduced from 0.8 to $0.2 \mathrm{~mL} / \mathrm{min}$, a maximum increase in detector response of 2,4-diaminopteridine-6-carboxylic acid was observed (Figure 6). At the same time, the response ratio of the two products was also changed. Hence, it could be postulated that any decrease in the flow-rate of the carrier stream will increase the residence time (reaction time) between the solid surface of CTH and the moving zone of MTX, whereas at higher flow-rates less fluorescent products could be produced and the recorded signal was decreased. The residence time between the sample zone containing MTX and the solid-phase reactor is very important for the reaction to proceed sufficiently and to achieve a substantial enhancement of the detector response. In the present work, a lower flow-rate was justified for the determination of MTX because peak enrichment could be achieved on the top of the analytical column (Hypersil ODS analytical column). As far as the oxidation reaction proceeded, 2,4-diaminopteridine-6-carboxaldehyde was converted into the corresponding 2,4-diaminopteridine6-carboxylic acid. Thus, it can be deduced that the signal of 2,4-diaminopteridine-6-carboxylic acid became more predominant when a lower flow rate was employed. The fluorescent products could be accumulated on the top of the analytical column with a zone width almost independent on the flow-rate of carrier stream. A compromise between analytical signal and sample frequency was established by choosing a working flow-rate of $0.2 \mathrm{~mL} /$ $\min$.

As a result, the optimal reaction conditions could be achieved by using phosphate buffer $(0.04 \mathrm{M}, \mathrm{pH} 3.4)$ at a flow-rate of $0.2 \mathrm{~mL} / \mathrm{min}$ and CTH column temperature of $40^{\circ} \mathrm{C}$.

\subsection{Effect of Sample Volume}

In an effort to push the concentration detection limit to a lower level, we attempted to use the analytical column head to pre-concentrate MTX by loading of a large sample volume of MTX to the packed CTH reactor. The design of a switching valve containing a packed reactor for on-line pre-column derivatization and sample enrichment was described (Figure 2, position A). Samples were loaded on to the CTH packed reactor with a carrier mobile phase (MI) and pump I, while pre-concentration was performed by means of the flow of the fluorescent products from the packed reactor to the analytical column head. Different injection volumes $(50-600 \mu \mathrm{L})$ were tested to introduce decreasing concentration of MTX. The efficiency of enrichment for MTX was evaluated on the basis of the linearity of calibration graph constructed over sample volumes $(50-600 \mu \mathrm{L}$, at $50 \mu \mathrm{L}$ interval). It was found that, the CTH packed reactor could tolerate large volumes of MTX standard solution and the linear relationship $\left(r^{2}\right.$ 0.9992) between the peak area and the injected volumes was observed over the range of 50 $500 \mu \mathrm{L}$ sample volume. If too large a sample is used (more than $500 \mu \mathrm{L}$ ), then the linearity of MTX between the peak area and concentration will be disturbed because 


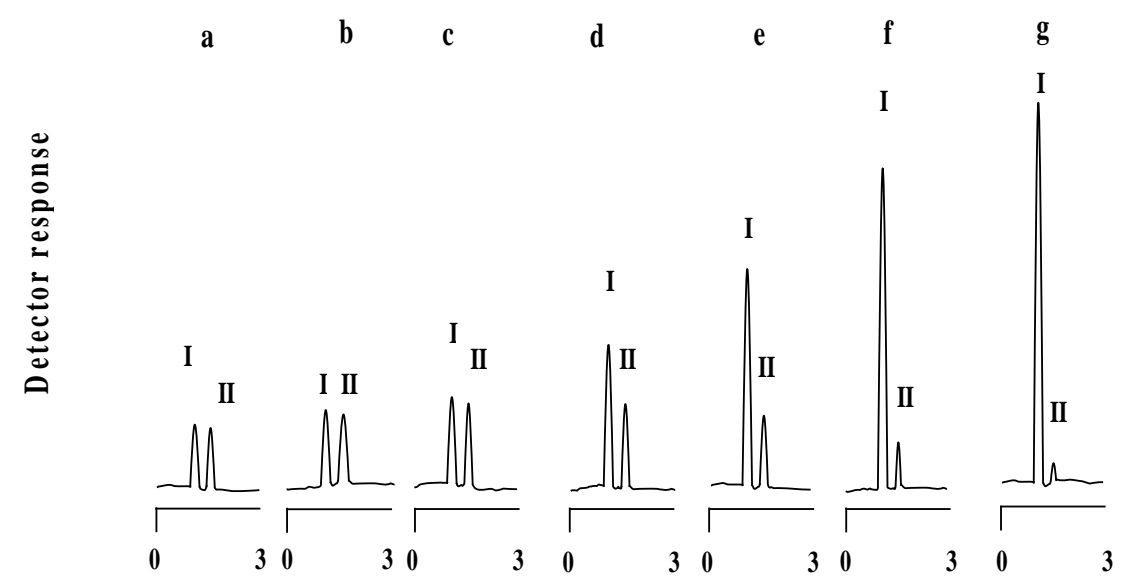

Figure 6. Chromatograms obtained after oxidative cleavage of MTX with CTH and fluorimetric detection (20 ng/mL). Peaks: I: 2,4-diaminopteridine-6-carboxylic acid; II: 2,4-diaminopteridine-6-carboxaldehyde. Flow rates: $0.8 \mathrm{~mL} / \mathrm{min}$ (a); $0.7 \mathrm{~mL} /$ $\min$ (b); $0.6 \mathrm{~mL} / \mathrm{min}$ (c); $0.5 \mathrm{~mL} / \mathrm{min}$ (d); $0.4 \mathrm{~mL} / \mathrm{min}$ (e); $0.3 \mathrm{~mL} / \mathrm{min}$ (f); $0.2 \mathrm{~mL} / \mathrm{min}$ (g).

a long residence time was found necessary to get reproducible results upon using large volume of MTX samples. Accordingly, sample volume of $500 \mu \mathrm{L}$ MTX sample was selected as a compromise between the sensitivity and accuracy. The pre-concentration was effective for the proposed method, achieving detection limit of $0.06 \mathrm{ng} /$ $\mathrm{mL}$ of MTX for a sample volume of $500 \mu \mathrm{L}$ with fluorescence detection.

\subsection{Optimization of the Chromatographic System}

Optimization studies for the oxidative cleavage of MTX with CTH were carried out in the presence of phosphate buffer (0.04 M, pH 3.4) aqueous carrier stream (MI). Also, HPLC experimental set-up required an optimum mobile phase (MII) composition to provide the necessary chromatographic separation of the compounds on the analytical column. It was noted that the $\mathrm{CTH}$ reactor needed a long equilibration time with $\mathbf{M I}$ after passing of any ethanol containing mobile phase (MII) through it. Thus, the system manifold was set up with columnswitching technique and two separate pumps to deliver MI and MII independently in order to eliminate such a long equilibration time (Figure 2).

The main objectives of the chromatographic step were to pre-concentrate and separate the highly fluorescent derivatives, 2,4-diaminopteridine-6-carboxaldehyde and the corresponding 2,4-diaminopteridine-6-carboxylic acid. The chromatographic separation was achieved on a short Thermo Scientific Hypersil ODS analytical column (100 $\mathrm{mm} \times 4.0 \mathrm{~mm}, 5 \mu \mathrm{m})$ using mixture of phosphate buffer (0.04 M, pH 3.4)-ethanol as MII. The optimization procedure was continued by changing the $\mathrm{pH}$ of $\mathrm{MII}$ as well as changing the ratios of phosphate buffer and ethanol.
Variation in the $\mathrm{pH}$ of mobile phase in the range of 2.0 6 weakly affected retention behavior of the fluorescent products. While variation of ethanol concentration strongly affected retention behaviors and band broadening. A green mobile phase of ethanol and phosphate buffer ( 0.04 $\mathrm{M}, \mathrm{pH} 3.4)(10: 90 \mathrm{v} / \mathrm{v})$ was found to give acceptable separation at a flow rate of $1.0 \mathrm{~mL} / \mathrm{min}$ and $25^{\circ} \mathrm{C}$ column temperature (Figure 6).

\subsection{Method Validation}

\subsubsection{Linearity}

The linearity was evaluated and established by triplicate analysis of the standard solutions of MTX. The obtained peak areas were plotted against the corresponding concentrations to generate calibration curve. Good linearity was evident $\left(r^{2}=0.9997\right)$ over the examined concentration range $1-40 \mathrm{ng} / \mathrm{mL}$. The equation for the best-fit straight line was determined by the linear regression analysis as $Y=\mathrm{a}+\mathrm{b} C$, where $Y$ is the peak area and $C$ denotes the concentration in $\mathrm{ng} / \mathrm{mL}$ of MTX. Characteristic parameters of the linear calibration curve are shown in Table 1.

\subsubsection{Limit of Detection and Quantification}

The limit of detection (LOD), defined as the lowest concentration of MTX that can be clearly detected above the base line signal, is estimated as three-times the signalto-noise ratio. The LOD was determined $(\mathrm{n}=3)$ by injection of MTX in decreasing concentrations. The LOD was found to be $0.06 \mathrm{ng} / \mathrm{mL}$ (Table 1). The LOQ is often defined as 10 times the signal-to-noise ratio. The LOQ was determined $(n=3)$ by injection of MTX in decreasing concentrations. The precision was calculated for each concentration. Then, the LOQ was calculated as the con- 
centration, where the precision was less than or equal to $15 \%$ and was found to be $0.20 \mathrm{ng} / \mathrm{mL}$ (Table 1).

\subsubsection{Precision and Accuracy}

The relative standard deviation (RSD \%) and the relative error (RE \%) of the mean measured concentration were served as measures of accuracy and precision for validation of the assay procedure. The intra- and inter-day assay precision and accuracy for MTX are summarized in Table 2. Within the examined range, the intra-day reproducibility and accuracy of the assay were excellent, with RSD \% being in the range of $0.23-0.28$ and with $\mathrm{RE} \%$ ranged from -0.33 to -0.49 . The inter-day RSD $\%$ were $0.26-0.32$ and the mean RE \% ranged from -0.36 to -0.56 . Repeatability and reproducibility of MTX samples with high and low concentration levels were below $0.60 \%$, indicating a reliable measurement using the proposed method (Table 2). RE was evaluated by backcalculation and expressed as the percent deviation between concentration added and concentration found according to the following:

$$
\mathrm{RE}=\frac{\text { concentration found }- \text { concentration added }}{\text { concentration added }} \times 100
$$

Table 1. Characteristic parameters for the regression equations of the proposed method ${ }^{\mathrm{a}}$.

\begin{tabular}{|c|c|}
\hline Parameters & MTX \\
\hline Calibration range $(\mathrm{ng} / \mathrm{mL})$ & $1-40$ \\
\hline Detection limit (ng/mL) & 0.06 \\
\hline Quantitation limit (ng/mL) & 0.20 \\
\hline Slope (b) & 1.4465 \\
\hline Standard error of the slope & 0.0104 \\
\hline Intercept (a) & 0.2421 \\
\hline Standard error of the intercept & 0.2149 \\
\hline Correlation coefficient $\left(r^{2}\right)$ & 0.9997 \\
\hline
\end{tabular}

Table 2. Precision and accuracy validation of MTX.

\begin{tabular}{lccc}
\hline & $\begin{array}{c}\text { Concentration } \\
(\mathrm{ng} / \mathrm{mL})\end{array}$ & $\begin{array}{c}\text { Recovery \% } \\
\text { RSD }\end{array}$ & Mean RE (\%) \\
\hline Intra-assay $^{\mathrm{a}}$ & 5 & $99.54 \pm 0.24$ & -0.46 \\
& 10 & $99.65 \pm 0.27$ & -0.35 \\
& 20 & $99.67 \pm 0.23$ & -0.33 \\
Inter-assay $^{\mathrm{a}}$ & 40 & $99.51 \pm 0.28$ & -0.49 \\
& 5 & $99.48 \pm 0.26$ & -0.52 \\
& 10 & $99.62 \pm 0.31$ & -0.38 \\
& 20 & $99.64 \pm 0.26$ & -0.36 \\
& 40 & $99.44 \pm 0.32$ & -0.56 \\
\hline
\end{tabular}

${ }^{\text {a }}$ Average of five determinations.

\subsubsection{Interference Studies}

In order to examine the selectivity of the proposed method, the effect of common excipients normally used in pharmaceutical formulations was studied. Solutions containing MTX $(20 \mathrm{ng} / \mathrm{mL})$ in the presence of more than 100 folds of common additives such as maize starch, calcium hydrogen phosphate, magnesium stearate, mannitol, red ferric oxide, lactose, methylhydroxypropylcellulose, sodium stearyl fumarate, microcrystalline cellulose, hydrophobic colloidal silica and sucrose were prepared. The undissolved materials were filtered off before injection. No significant changes were observed on the results and recoveries in the range of $99.42 \%-99.75 \%$ were obtained in all cases.

\subsection{Drug Content Analysis}

The proposed on-line pre-column oxidative cleavage method was applied for the determination of MTX in its commercial formulations together with the official USP method [30]. As indicated, the assay results obtained by the proposed method were in accordance with those obtained by the official method. The accuracy and precision of the developed method were further judged by applying $t$ - and $F$-test at $95 \%$ confidence level. The experimental $t$ - and $F$-values did not exceed the theoretical values, which support the similar accuracy and precision of the proposed and official USP methods (Table 3). The accuracy and precision of the developed method were further judged by applying $t$ - and $F$-test at $95 \%$ confidence level. The experimental $t$ - and $F$-values did not exceed the theoretical values, which support the similar accuracy and precision of the proposed and official USA methods (Table 3).

Table 3. Determination of MTX in commercial formulations by the proposed and official methods.

\begin{tabular}{ccc}
\hline \multirow{2}{*}{ Commercial formulation } & \multicolumn{2}{c}{ Recovery $(\%)^{\mathrm{a}} \pm$ RSD } \\
\cline { 2 - 3 } & Proposed method & Official method \\
\hline Tablets $(20 \mathrm{ng} / \mathrm{mL})$ & $99.84 \pm 0.34$ & $99.86 \pm 0.30$ \\
Student's $t$-test & $0.09(2.30)^{\mathrm{b}}$ & \\
F-test & $1.22(6.38)^{\mathrm{b}}$ \\
Vials $(20 \mathrm{ng} / \mathrm{mL})$ & $99.85 \pm 0.27$ & $99.87 \pm 0.29$ \\
& $0.13(2.30)^{\mathrm{b}}$ & \\
& $1.14(6.38)^{\mathrm{b}}$ \\
Recovery $(\%)^{\mathrm{c}} \pm \mathrm{RSD}$ & \\
Tablets & $99.48 \pm 0.35$ \\
Vials & $99.50 \pm 0.32$ \\
\hline
\end{tabular}

${ }^{a}$ Average of five determinations; ${ }^{b}$ Theoretical values at $\mathrm{p}=0.05$; ${ }^{\mathrm{c}}$ For standard addition of $50 \%$ of the nominal content. 
Mean value are very close to the theoretical concentrations, showing method \% recoveries from 99.48 to 99.50 and RSD from 0.32 to 0.35 . These results indicate that the effects of the common additives and ingredients of the pharmaceutical formulations do not interfere with the determination of MTX.

\subsection{Robustness}

To determine robustness of the proposed method, experimental conditions such as flow-rate, $\mathrm{pH}$ and concentration of the buffer solution used as a carrier stream, packed reactor temperature and organic content of the mobile phase were purposely altered and the detector responses were evaluated. Variation of each parameter by $\pm 2 \%$ did not have a significant effect on the detector response.

\section{Conclusion}

In this study, a green on-line pre-column oxidation-SPEnHPLC separation strategy using a packed oxidant reactor of CTH and a short Hypersil ODS analytical column $(100 \mathrm{~mm} \times 4.0 \mathrm{~mm}$ i.d.) has been developed to determine low levels of MTX. The method was a powerful analyticcal technique that had excellent sensitivity, sufficient accuracy and required relatively simple and inexpensive instrumentation. These advantages made the proposed method an attractive procedure for the routine quality control and dosage form analysis of MTX at very low concentration level, down to $0.20 \mathrm{ng} / \mathrm{mL}$. The applicability of this method was evaluated by the determination of MTX in pharmaceutical formulations. Common excipients used as additives in pharmaceutical preparations did not interfere. Furthermore, the proposed method is worthy contributed to the existing environmental friendly analytical chemistry due to reducing or elimination of the use and generation of hazardous substances.

\section{REFERENCES}

[1] S. Shen, T. O’Brien, L. M. Yap, H. M. Prince and C. J. McCormack, "The Use of Methotrexate in Dermatology: A Review," Australasian Journal of Dermatology, Vol. 53, No. 1, 2102, pp. 1-18.

[2] M. Bărcă, M. Ilie, D. L. Baconi, A. M. Ciobanu, D. Bălălău and G. T. Burcea, "Spectrofluorimetric Methotrexate Assay in Human Plasma," Farmacia, Vol. 58, No. 1, 2010, pp. 95-101.

[3] S. M. Sabry, M. Abdel-Hady, M. Elsayed, O. T. Fahmy and H. M. Mahr, "Study of Stability of Methotrexate in Acidic Solution. Spectrofluorimetric Determination of Methotrexate in Pharmaceutical Preparations through AcidCatalyzed Degradation Reaction," Journal of Pharmaceutical and Biomedical Analysis, Vol. 32, No. 3, 2003, pp. 409-423. doi:10.1016/S0731-7085(03)00239-5

[4] A. Espinosa-Mansilla, I. Durán Merás, A. Zamora Madera, L. Pedano and C. Ferreyra, "Kinetic Fluorimetric Determination of the Antineoplastic Methotrexate (MTX) in Human Serum," Journal of Pharmaceutical and Biomedical Analysis, Vol. 29, No. 5, 2002, pp. 851-858. doi:10.1016/S0731-7085(02)00212-1

[5] H. Hayashi, C. Fujimaki, S. Tsuboi, T. Matsuyama, T. Daimon and K. Itoh, "Application of Fluorescence Polarization Immunoassay for Determination of MethotrexatePolyglutamates in Rheumatoid Arthritis Patients," The Tohoku Journal of Experimental Medicine, Vol. 215, No. 1, 2008, pp. 95-101. doi:10.1620/tjem.215.95

[6] H. L. Cheng, S. S. Chiou, Y. M. Liao, C. Y. Lu, Y. L. Chen and $\mathrm{S} . \mathrm{M}$. $\mathrm{Wu}$, "Analysis of Methotrexate and Its Eight Metabolites in Cerebrospinal Fluid by Solid-Phase Extraction and Triple-Stacking Capillary Electrophoresis," Analytical and Bioanalytical Chemistry, Vol. 398, No. 5, 2010, pp. 2183-2190.

doi:10.1007/s00216-010-4152-3

[7] H. L. Cheng, Y. M. Liao, S. S. Chiou and S. M. Wu, "OnLine Stacking Capillary Electrophoresis for Analysis of Methotrexate and Its Eight Metabolites in Whole Blood," Electrophoresis, Vol. 29, No. 17, 2008, pp. 3665-3673. doi:10.1002/elps.200800029

[8] S. Fang, C. P. Lollo, C. Derunes and M. J. LaBarre, "Development and Validation of a Liquid Chromatography Method for Simultaneous Determination of Three Process-Related Impurities: Yeastolates, Triton X-100 and Methotrexate," Journal of Chromatography B, Vol. 879, No. 30, 2011, pp. 3612-3619. doi:10.1016/j.jchromb.2011.10.003

[9] E. Klapkova, J. Kukacka, K. Kotaska, I. Suchanska, R. Urinovska and R. Prusa, "The Influence of 7-OH Methotrexate Metabolite on Clinical Relevance of Methotrexate Determination," Clinical Laboratory, Vol. 57, No. 7-8, 2011, pp. 599-606.

[10] K. Michail and M. S. Moneeb, "Determination of Methotrexate and Indomethacin in Urine Using SPE-LC-DAD after Derivatization," Journal of Pharmaceutical and Biomedical Analysis, Vol. 55, No. 2, 2011, pp. 317-324. doi:10.1016/i.jpba.2011.01.032

[11] L. Hu, Y. Liu and S. Cheng, "Simultaneous Determination of Six Analytes by HPLC-UV for High Throughput Analysis in Permeability Assessment," Journal of Chromatographic Science, Vol. 49, No. 2, 2011, pp. 124-128. doi:10.1093/chrsci/49.2.124

[12] T. Sartori, F. S.Murakami, A. P. Cruz and A. M. de Campos, "Development and Validation of a Fast RP-HPLC Method for Determination of Methotrexate Entrapment Efficiency in Polymeric Nanocapsules," Journal of Chromatographic Science, Vol. 46, No. 6, 2008, pp. 505-509.

[13] D. A. el-Hady, N. A. el-Maali, R. Gotti, C. Bertucci, F. Mancini and V. Andrisano, "Methotrexate Determination in Pharmaceuticals by Enantioselective HPLC," Journal of Pharmaceutical and Biomedical Analysis, Vol. 37, No. 5, 2005, pp. 919-925. doi:10.1016/i.jpba.2004.07.046

[14] M. Uchiyama, T. Matsumoto, T. Matsumoto, S. Jimi, Y. 
Takamatsu, K. Tamura and S. Hara, "Simple and Sensitive HPLC Method for the Fluorometric Determination of Methotrexate and Its Major Metabolites in Human Plasma by Post-Column Photochemical Reaction," Biomedical Chromatography, Vol. 26, No. 1, 2012, pp. 76-80. doi:10.1002/bmc. 1628

[15] L. van Haandel and J. F. Stobaugh, "Bioanalytical Method Development for a Generation 5 Polyamidoamine Folic Acid Methotrexate Conjugated Nanoparticle," Analytical and Bioanalytical Chemistry, Vol. 397, No. 5, 2010, pp. 1841-1852. doi:10.1007/s00216-010-3716-6

[16] S. Chen and Z. Zhang, "Molecularly Imprinted SolidPhase Extraction Combined with Electrochemical Oxidation Fluorimetry for the Determination of Methotrexate in Human Serum and Urine," Spectrochimica Acta Part A, Vol. 70, No. 1, 2008, pp. 36-41. doi:10.1016/j.saa.2007.07.009

[17] H. Li, W. Luo, Q. Zeng, Z. Lin, H. Luo and Y. Zhang, "Method for the Determination of Blood Methotrexate by High Performance Liquid Chromatography with Online Post-Column Electrochemical Oxidation and Fluorescence Detection," Journal of Chromatography B, Vol. 845, No. 1, 2007, pp. 164-168. doi:10.1016/j.jchromb.2006.07.026

[18] I. Durán Merás, A. Espinosa Mansilla and M. J. Rodríguez Gómez, "Determination of Methotrexate, Several Pteridines, and Creatinine in Human Urine, Previous Oxidation with Potassium Permanganate, Using HPLC with Photometric and Fluorimetric Serial Detection," Analytical Biochemistry, Vol. 346, No. 2, 2005, pp. 201-209. doi:10.1016/j.ab.2005.07.038

[19] E. A. McCrudden and S. E. Tett, "Improved High-Performance Liquid Chromatography Determination of Methotrexate and Its Major Metabolite in Plasma Using a Poly (Styrene-Divinylbenzene) Column," Journal of Chromatography $B$, Vol. 721, No. 1, 1999, pp. 87-92. doi:10.1016/S0378-4347(98)00439-3

[20] Z. Yu, D. Westerlund and K. S. Boose, "Determination of Methotrexate and Its Metabolite 7-Hydroxymethotrexate by Direct Injection of Human Plasma into a ColumnSwitching Liquid Chromatographic System Using PostColumn Photochemical Reaction with Fluorimetric Detection," Journal of Chromatography B, Vol. 689, No. 2, 1997, pp. 379-386. doi:10.1016/S0378-4347(96)00357-X

[21] T. Suzuki, H. Hashimoto and N. Ichinose, "Microanalysis of Methotrexate by High-Performance Liquid Chromatography Using a Fluorescence Detector," Fresenius Journal of Analytical Chemistry, Vol. 351, No. 8, 1995, pp. 806-807. doi:10.1007/BF00323644
[22] H. Kubo, Y. Umiguchi, M. Fukumoto and T. Kinoshita, "Fluorimetric Determination of Methotrexate in Serum by High-Performance Liquid Chromatography Using in-Line Oxidation with Hydrogen Peroxide," Analytical Sciences, Vol. 8, No. 6, 1992, pp. 789-792. doi:10.2116/analsci.8.789

[23] J. Šalamoun, M. Smrž, F. Kiss and A. Šalamounová, "Column Liquid Chromatography of Methotrexate and Its Metabolites Using a Post-Column Photochemical Reactor and Fluorescence Detection," Journal of Chromatography B, Vol. 419, 1987, pp. 213-223. doi:10.1016/0378-4347(87)80279-7

[24] J. Šalamoun and J. František, "Determination of Methotrexate and Its Metabolites 7-Hydroxymethotrexate and 2,4-Diamino- $\mathrm{N}^{10}$-methylpteroic Acid in Biological Fluids by Liquid Chromatography with Fluorimetric Detection," Journal of Chromatography B, Vol. 378, No. 1, 1986, pp. 173-181.

[25] J. A. Nelson, B. A. Harris, W. J. Decker and D. Farquhar, "Analysis of Methotrexate in Human Plasma by HighPerformance Liquid Chromatography with Fluorescence Detection," Cancer Research, Vol. 37, No. 11, 1977, pp. 3970-3973.

[26] S. Chen, Z. Zhang, D. He, Y. Hu, H. Zheng and C. He, "Flow-Injection-Electrochemical Oxidation Fluorimetry for Determination of Methotrexate," Luminescence, Vol. 22, No. 4, 2007, pp. 338-342. doi:10.1002/bio.968

[27] S. Emara, "Determination of Methotrexate in Pharmaceutical Formulations by Flow Injection Analysis Exploiting the Reaction with Potassium Permanganate," II Farmaco, Vol. 59, No. 10, 2004, pp. 827-833. doi:10.1016/i.farmac.2004.06.005

[28] R. I. Stefan, R. G. Bokretsion, J. F. van Staden and H. Y. Aboul-Enein, "Simultaneous Determination of L- and DMethotrexate Using a Sequential Injection Analysis/Amperometric Biosensors System," Biosensors and Bioelectronics, Vol. 19, No. 3, 2003, pp. 261-267. doi:10.1016/S0956-5663(03)00210-0

[29] S. Emara, S. Razee, A.-N. El-Shorbagy and T. Masujima, "Flow Injection Method for the Determination of Methotrexate with a Column-Packed Oxidizing Agent," Analyst, Vol. 121, No. 2, 1996, pp. 183-188. doi:10.1039/an9962100183

[30] United States Pharmacopeial Convention, "The United States Pharmacopeia and National Formulary (USP 28-NF 23)," The Official Compendia of Standards, Asian Edition, The United States Pharmacopeial Convention Inc., Rockville, 2005. 